\title{
KEYSTONES
}

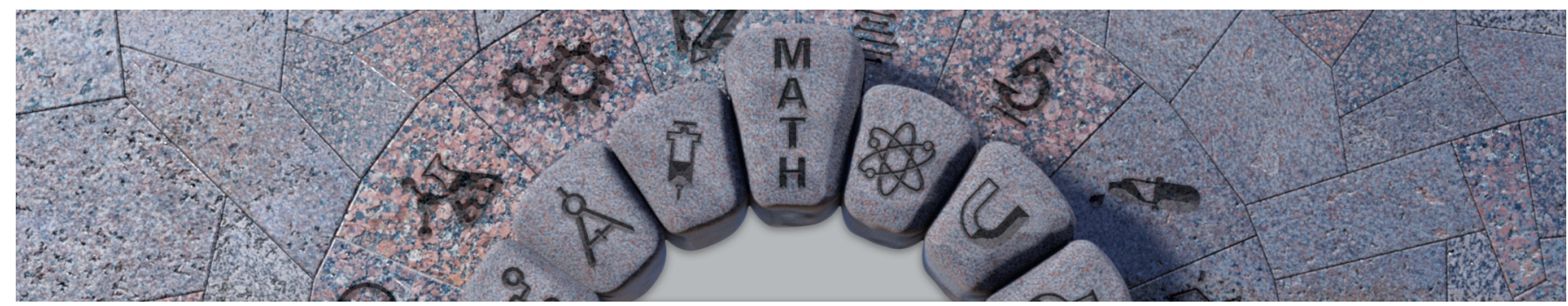

\section{Mathematics in the Theory and Practice of Auctions}

\section{Hector Lopez}

An auction is the practice of selling items by collecting bids and assigning the items to the highest bidders. ${ }^{1}$ Nowadays, auctions are a ubiquitous transactional method in many industries used by governments, companies, and individuals. Governments use auctions to sell financial securities, and many rights such as timber, oil, gas, minerals, and electromagnetic spectrum. Companies use auctions to sell commodities such as fish, flowers, diamonds, and milk, and digital goods such as keyword positions and advertisement-every time anyone interacts with the internet an auction is run to serve the best content and best advertisement. Individuals participate in auctions, too. Houses are commonly sold to the highest bidder-a fact that may be notoriously salient to anyone buying or selling this year.

An auction's main job is to allocate items to the bidders who value them the most. For example, in the most common auction format, the open ascending auction, an auctioneer sells a single item by collecting bids from an audience, increasing the price until only one bidder remains interested. This auction allocates the item to the bidder who values it the most because the bidder with the greatest value can outbid all other bidders. However, in theory and in

Hector Lopez is an associate director at NERA Economic Consulting. His email address is hector.1opez@nera.com.

Communicated by Notices Associate Editor Emilie Purvine.

${ }^{1}$ Auctions are also used to buy from the lowest bidders.

For permission to reprint this article, please contact: reprint-permission aams.org.

DOI: https://dx.doi.org/10.1090/noti2374 practice, achieving this goal is (extremely) hard when there are multiple items to be sold because it involves solving many complex challenges; for example, solving computationally complex combinatorial problems, incentivizing bidders to bid sincerely, exchanging information, fostering participation, preventing collusion, facilitating fairness, among others. In this paper, I highlight only some elements considered in the theory and practice of auctions regarding computations, behavior, and information.

To appreciate these challenges, consider an auction for a set $M$ of items and a group $N$ of bidders. Each bidder $i$ has a valuation $v_{i}(s)$ for every subset $s$ of $M$. An efficient auction's job is to find pairwise disjoint sets $s_{i}$ such that the bidders' total value $\sum_{i \in N} v_{i}\left(s_{i}\right)$ is maximized. ${ }^{2}$

The first challenge is computational. Assuming that the auctioneer already has values for all subsets for all bidders, solving the winner determination problem is very hard-NPhard in general.

The second challenge is behavioral. The auctioneer does not know the bidders' values $v_{i}(s)$. The auctioneer can request bids $b_{i}(s)$, and bidders can send whatever bids they want (or none for a given $s$ ). The auctioneer must incentivize bidders to provide bids such that the set of $s_{i}$ that maximizes $\sum_{i \in N} b_{i}\left(s_{i}\right)$ also maximizes $\sum_{i \in N} v_{i}\left(s_{i}\right)$. Incentives are usually provided by specifying a payment function that determines what each bidder must pay as a function of the whole set of received bids. At this level of generality,

\footnotetext{
${ }^{2}$ In this paper I focus on "efficient auctions." Auctions can also be used to maximize revenues or other objectives.
} 
providing such payment functions seems Nobel-prize-worthy; and indeed a Nobel was awarded to William Vickrey in 1996 [1], [2].

The third challenge is informational. In many instances, bidders themselves do not know their own valuation functions. For example, the set of items could be a collection of spectrum licenses and the set of bidders could be telecommunications companies. Bidders must spend resources to discover how much value would be added to the company by a given set of licenses [3]. In addition, even if the bidder knows its valuation for all subsets, and is willing to provide bids for all subsets, how can the bids be transmitted to the auctioneer if there are many items? $-2^{M}$ gets impractically large very quickly.

Given these challenges, how is it possible that auctions are frequently and successfully run? The answer: very detailed theoretical, computational, experimental, and practical analysis of the very items and valuations structures at hand. Every situation demands a particular auction format: a detailed set of rules that describes what bids are valid, how the bids are transmitted, how the winners are selected, how the payments are calculated, etc.

One of the most common and celebrated auction formats today is the simultaneous multiple round auction (SMRA). The SMRA format was created by Paul Milgrom and Robert Wilson-the 2020 winners of the Nobel prize in Economics "for improvements to auction theory and inventions of new auction formats." The Federal Communications Commission (FCC) has run over one hundred auctions since 1994 using the SMRA (and closely related formats). A typical FCC auction involves thousands of items and billions of dollars [4].

In a nutshell, the SMRA works as follows. Bidders can submit bids $b_{i}(m)$ for each item $m$ in a sequence of rounds. All items are offered in all rounds. Each round, the highest bid for each item is provisionally selected as winner. Bidders can bid for a nonincreasing number of items as rounds progress. ${ }^{3}$ The auction concludes on the first round with no new bids. Provisionally winning bids become winners, and bidders pay their winning bids.

How does the SMRA solve the three challenges?

The computational challenge is solved by the gradual approximation of the solution round by round. Akin to a greedy algorithm, the SMRA maximizes the total value of the bids by tentatively assigning winners each round until there is a round with no value improvement-with no new bids.

The behavioral challenge is (mostly) solved by requiring the lowest possible payments. Since the SMRA ends when there is no new bid, a winning bidder only needs to pay a price equal to the value of the highest losing bid. When the price that a bidder effectively pays does not depend on its bid, it is in its best interest to continue bidding until

\footnotetext{
${ }^{3}$ This is a gross simplification of the so-called activity rule. See [5].
}

its true valuation is reached. This independence between bid and payment does not always hold in the SMRA [6]. It is possible that some bidders may have an opportunity to influence their payment by misrepresenting its values. However, not all misrepresentations will produce a misallocation of items, and these opportunities vanish as the number of bidders increases [7]

The informational challenge is solved by conducting the auction using many rounds and by requesting bids for individual items. Each round, bidders can use the tentative winning bids as prices to figure out the relevant valuations. Each round, bids are at most $M$ numbers.

The SMRA is efficient when the bidders consider the items to be substitutes and bidders bid their valuations [5]. ${ }^{4}$ This theoretical result has had great influence on practice. Bidders and auctioneers debate the substitutability of the items every auction, and on the merits of the SMRA versus other formats given the likelihood of misrepresentation opportunities. If the consensus is that items are reasonable substitutes and the misrepresentation opportunities are limited, then the SMRA or one of its variants is adopted.

The influence of theory in the practice of auctions is not limited to one result for one format. Theory is a core tool in the practice of auctions. It is common for bidders, auctioneers, and their consultants to argue about the set of theoretical results in auction theory (optimization, computer science, game theory) that favor one format over another in a given situation, and even the particular mathematical formulations describing a given rule [9], [10].

Analogously, practice is an essential inspiration for theory. Every new practical problem spurs new research to obtain a tractable and efficient auction format for the problem at hand.

I believe that the virtuous cycle between theory and practice will continue for years to come, opening the door to academics and practitioners in many fields to continue making significant contributions to the theory and practice of auctions.

\section{References}

[1] William Vickrey, Counterspeculation, auctions, and competitive sealed tenders, J. Finance 16 (1961), no. 1, 8-37.

[2] https://www. nobe1prize.org/prizes/economic -sciences/1996

[3] Kate Larson and Tuomas Sandholm, Costly valuation computation in auctions, Proceedings of Theoretical Aspects of Rationality and Knowledge (TARK VIII), 2001, pp. 169182.

[4] https://www.fcc.gov/auctions-summary

\footnotetext{
${ }^{4}$ Items are substitutes for a bidder whenever she does not stop demanding some items because the price of other items have increased. The result holds when items are substitutes for all bidders. There are alternative definitions of sustainability that guarantee similar results. For example, if the value of a set of items is at most the sum of the value of its parts, then the SMRA is approximately efficient. See [8].
} 
[5] Paul Milgrom, Putting auction theory to work: The simultaneous ascending auction, J. Political Economy 108 (2000), no. 2, 245-272.

[6] Lawrence M. Ausubel, Peter Cramton, Marek Pycia, Marzena Rostek, and Marek Weretka, Demand reduction and inefficiency in multi-unit auctions, Rev. Economic Studies 81 (2014), no. 4, 1366-1400.

[7] Eduardo M. Azevedo and Eric Budish, Strategy-proofness in the large, Rev. Economic Studies 86 (2019), no. 1.

[8] Michal Feldman, Hu Fu, Nick Gravin, and Brendan Lucier, Simultaneous auctions without complements are (almost) efficient, Games and Economic Behavior 123 (2020), 327341.

[9] https://wireless.fcc.gov/auctions/incentive -auctions/DA-15-1183_Appendix_C_update.pdf

[10] https://www.fcc.gov/fi]es/da-15-1183appendixg updatepdf

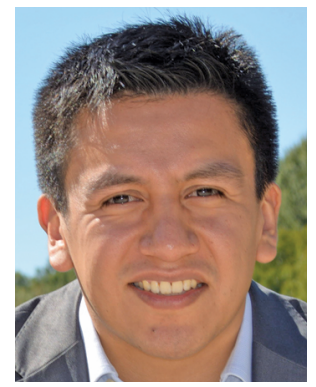

Hector Lopez

\section{Credits}

Author photo is courtesy of María Cruz Carbajal.

\section{Apply to Become an ICERM Postdoctoral Fellow}

The Institute for Computational and Experimental Research in Mathematics (ICERM) at Brown University invites applications for its 2022-2023 postdoctoral positions.

Postdoctoral Institute Fellows: ICERM supports two academic-year Postdoctoral Institute Fellows with salary and benefits.

Postdoctoral Semester Fellows: ICERM supports five four-month Postdoctoral Fellows each semester with salary and benefits.

The 2022-2023 Semester Programs are:

- Harmonic Analysis and Convexity (Fall)

- Modern Discrete Optimization: Mathematics, Algorithms, and Computation (Spring)

Eligibility for all ICERM Postdoctoral positions: Applicants must have completed their Ph.D. within three years of the start of the appointment. Documentation of completion of all requirements for a doctoral degree in mathematics or a related area by the start of the appointment is required.

For full consideration: applicants must submit an AMS Standard Cover Sheet, curriculum vitae (including publication list), cover letter, research statement, and three letters of recommendation by early January, 2022, to MathJobs.org (search under "Brown University").

Brown University is committed to fostering a diverse and inclusive academic global community; as an EEO/AA employer, Brown considers applicants for employment without regard to, and does not discriminate on the basis of, gender, sex, sexual orientation, gender identity, national origin, age, race, protected veteran status, disability, or any other legally protected status.

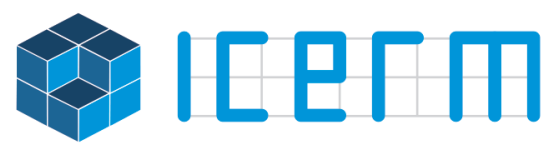

Institute for Computational and Experimental Research in Mathematics

Proposals being accepted: Semester Program

Topical Workshop

Small Group Research Program

Summer Undergrad Program

ICERM is a National Science Foundation Mathematics Institute at Brown University in Providence, RI.
Appications being accepted: Semester Program or Workshop Postdoctoral Fellowship

Sponsorships being accepted: Academic or Corporate

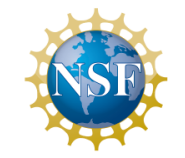

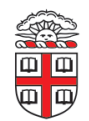

BROWN

\section{icerm.brown.edu}

